\title{
Determination of the Normal Anal Location in Neonates: A Prospective Cross-Sectional Study
}

\author{
๑ Sinan Tufekci, ๑ Ebru Yesildag* \\ Tekirdag Namık Kemal University Faculty of Medicine, Department of Pediatrics, Division of Neonatology, Tekirdag, Turkey \\ *Tekirdag Namık Kemal University Faculty of Medicine, Department of Pediatric Surgery, Tekirdag, Turkey
}

\section{Abstract}

Aim: Anterior displacement of the anus might be a form of anorectal malformations. The study aims to measure the anal position index (API) in neonates with a modified method.

Methods: The study was conducted between March 1, and December 31, 2019, in the neonatal unit at Tekirdag Namık Kemal University Hospital. The neonates between 35 and 42 gestational weeks and those without congenital malformation were included in the study. Four hundred five neonates were evaluated prospectively. API was determined by using distances between posterior fourchette - anus and posterior fourchette - coccyx in girls; scrotum - anus, and scrotum - coccyx in boys.

Results: Of 405 participants, there were 230 males. API was found $0.52 \pm 0.05$ and $0.39 \pm 0.04$ in boys and girls, respectively. For the diagnosis of the anterior location of the anus, the lower limit was $0.33 \mathrm{~cm}$ in girls and $0.43 \mathrm{~cm}$ in boys. According to these results, nine boys (3.9\%) and seven girls (4\%) had an anteriorly located anus.

Conclusion: API could be measured more accurately by the modified method and this resulted in a lower incidence of anterior location when compared with the previously defined techniques.

Keywords: Newborn, anorectal malformation, constipation

\section{Introduction}

Constipation is a common problem in infancy and childhood. The main reason for it in the pediatric population is dietary irregularities. Toilet training also has an important effect in preventing constipation. Besides functional constipation, the anatomic abnormalities of the anal region can also lead to difficulty in defecation. Anorectal malformations are one of those common congenital anomalies in pediatric surgery. The etiology is unknown and the incidence is reported to be $1 / 2000$ $1 / 5000$ (1). It is especially together with other system anomalies (2-4). Anorectal malformations (ARM) lead to a spectrum of symptoms ranging from fecal incontinence to severe constipation (5-6). The higher type ARM, in which some serial operations are indicated, generally results in fecal incontinence. The lower type anomalies, on the other hand, may present with constipation as the normal propagation of stool is not allowed (7). On the other hand, some studies confirmed no relation with constipation. The anomaly, especially the higher type, might be detected prenatally in $16 \%$ of the cases (3). But generally, the diagnosis of ARM is made with the initial examination of the neonate just after the delivery.

The normal location of the anal opening is defined to be the midpoint of the distance between the coccyxvaginal fourchette or coccyx-distal scrotum. This is an anatomic definition but the most important aspect of this location is its relation with the sphincter complex (8). Anteriorly located anus may be diagnosed with inspection but there might have difficulties if the standard measures are not used, especially in minor forms (9-10). Reisner et al. (8) described a quantitative measuring method in 1984. They suggested the lower limit of 0.34 and 0.46 in girls and boys, respectively for the diagnosis of the anterior location (8). The limits for an anterior displacement of the anus were reported to be $<0.44$ in girls and $<0.53$

Address for Correspondence: Sinan Tufekci, Tekirdag Namık Kemal University Faculty of Medicine, Department of Pediatrics, Division of Neonatology, Tekirdag, Turkey Phone: +90 5324417882 E-mail: stufekci@nku.edu.tr ORCID: orcid.org/0000-0003-0367-3828 Received: 11.03.2021 Accepted: 17.04.2021 
in boys in the study of Davari and Hosseinpour (11). The normal ranges of anal position index (API) were different in different studies and differences between ethnic groups were detected $(11,12)$.

The study aims to evaluate the anal location using API measurement in otherwise healthy neonates and to make the comparison with the prior studies.

\section{Methods}

\section{Study Design}

The study was planned prospectively and approval was obtained from the local Ethics Committee (Protocol No: 2019.24.02.08). The study conformed to the ethical guidelines of the 1975 Declaration of Helsinki and written informed consent was obtained from the legal guardians of all the patients before enrollment.

The babies who were born between March 1December 31, 2019, and examined in the Tekirdag Namık Kemal University neonatal unit were included in the study. The exclusion criteria were the existence of chromosomal abnormalities $(n=1)$, anencephaly $(n=1)$, congenital heart diseases $(n=3)$, congenital malformations $(n=2)$, ambiguous genitalia $(n=1)$, congenital spine deformities $(n=1)$, extremity deformities such as achondroplasia $(n=1)$.

The baby born before $37^{0 / 7}$ gestational weeks was accepted to be preterm; born between $37^{0 / 7}-38^{6 / 7}$ and at/ after $39^{0 / 7}$ gestational weeks were early term and lateterm, respectively. The age of the mother, type of delivery, birth height/weight/head circumference in girls and boys, the age at pregnancy, body mass index (BMI) (weight/ height $\left.{ }^{2}\right), A P G A R$ scores in the first and fifth minute, and the time of meconium passage were evaluated. All these data of the patients were obtained from the hospital records.

\section{Anal Position Index Measurement}

The neonate was in a supine position with both proximal lower extremities were in extension abduction. The longitudinal axis in the midline of the perineum together with the anus was covered with transparent adhesive tape. The anal circle and the lower/upper limits were marked. All the measurements were made by the same neonatologist. In girls, API was detected with the proportion between distances of the posterior fourchette to the anus and posterior fourchette to the coccyx. It was calculated using the distances between the scrotal base to the anus and the scrotal base to the coccyx in boys (Figure 1, drawn by the authors).

\section{Statistical Analysis}

The compatibility of the variables to normal distribution was evaluated with histogram graphics and the Kolmogorov-Smirnov test using Statistical Package for the Social Sciences version 17.0 program. The mean, standard deviation, and median values were used while presenting descriptive analyzes. Categorical variables were compared with the Pearson chi-square test. Variables that are not normally distributed (nonparametric) were evaluated in two and more than two groups by using Mann-Whitney $\mathrm{U}$ test and the Kruskal-Wallis test, respectively. Spearman correlation test was used in the analysis of measurement data. $\mathrm{P}<0.05$ was considered statistically significant.

\section{Results}

The demographics and clinical features are presented in Table 1. There were 230 (57\%) boys and $175(43 \%)$ girls. The $52(13 \%)$ of them were preterm, while 202 (50\%) and 151 (37\%) were early term and late term, respectively. Normal vaginal delivery was detected in 96 (24\%) of them. The mean gestational age was $38.4 \pm 1.3$ weeks. Birth weight ranged between $3130.0 \pm 475.8$ grams. The height and head circumference at birth were found to be $49.3 \pm 2.5$ and $34.5 \pm 1.8 \mathrm{~cm}$. The mean maternal age was $29.2 \pm 5.8$ years.

Table 2 documents the percentile scale of API values in the presented series. The values detected below the fifth percentile were used in the diagnosis of the anterior location of the anus after measuring API in all the neonates. These values were $<0.33 \mathrm{~cm}$ and $<0.43 \mathrm{~cm}$ in

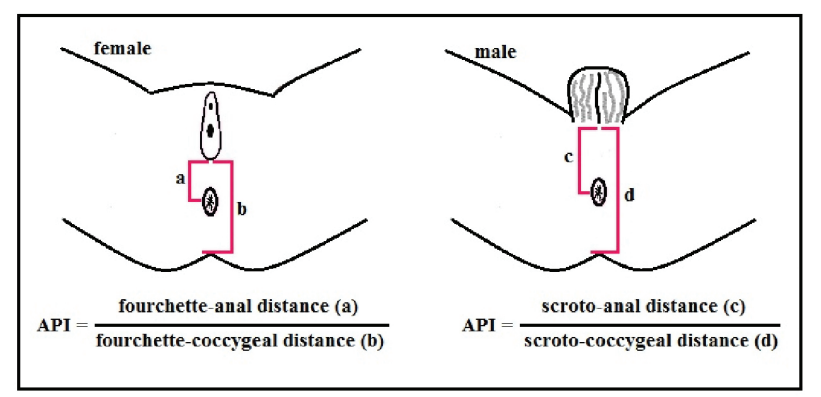

Figure 1. The method of measuring anal position index in girls and boys

API: Anal position index

\begin{tabular}{|l|l|}
\hline \multicolumn{2}{|l|}{ Table 1. The demographic and clinical features of the patients } \\
\hline Features & mean \pm SD \\
\hline Gestational age (weeks) & $38.4 \pm 1.3$ \\
\hline Birth weight (gram) & $3130 \pm 475.8$ \\
\hline Birth height (cm) & $49.3 \pm 2.5$ \\
\hline Birth head circumference (cm) & $34.5 \pm 1.8$ \\
\hline Body mass index & $1.28 \pm 0.13$ \\
\hline Maternal age & $29.2 \pm 5.8$ \\
\hline First day of admittance (day) & $4.3 \pm 6.8$ \\
\hline The time of meconium passage (hour) & $10.5 \pm 8.4$ \\
\hline Apgar score 1. minute & 8 (median) \\
\hline Apgar score 5. minute & 9 (median) \\
\hline SD: Standard deviation & \\
\hline
\end{tabular}




\begin{tabular}{|l|l|l|}
\hline \multicolumn{3}{|l|}{ Table 2. Anal position index percentile in males and females } \\
\hline API $^{1}$ & males & females \\
\hline Percentile 05 & 0.43 & 0.33 \\
\hline Percentile 25 & 0.49 & 0.36 \\
\hline Percentile 50 & 0.52 & 0.38 \\
\hline Percentile 75 & 0.55 & 0.42 \\
\hline Percentile 95 & 0.60 & 0.46 \\
\hline Percentile 99 & 0.67 & 0.51 \\
\hline 'API: Anal position index & \\
\hline
\end{tabular}

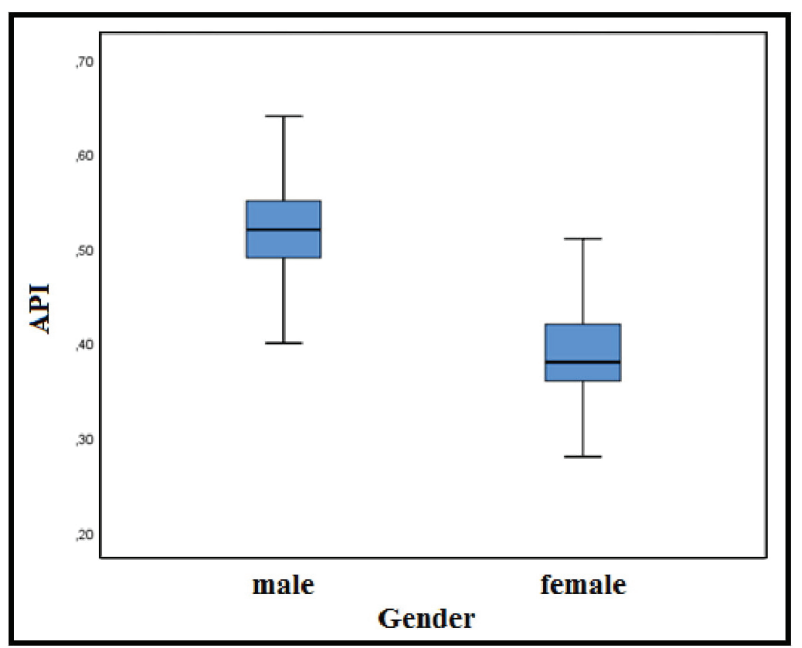

Figure 2. The anal position index values in different genders API: Anal position index

\begin{tabular}{|l|l|l|l|l|l|}
\hline \multicolumn{6}{|l|}{ Table 3. Measurement results of the patients } \\
\hline Features & Mean & $\begin{array}{l}\text { Standard } \\
\text { deviation }\end{array}$ & Median & $\begin{array}{l}\mathbf{9 5 \%} \mathbf{C l}^{*} \\
\text { Lower } \\
\text { limit }\end{array}$ & $\begin{array}{l}\text { 95\% Cl } \\
\text { Upper } \\
\text { limit }\end{array}$ \\
\hline $\begin{array}{l}\text { Scrotum-Anus } \\
(\mathrm{cm})\end{array}$ & 2.87 & \pm 0.49 & 2.90 & 2.81 & 2.94 \\
\hline $\begin{array}{l}\text { Scrotum-Coccyx } \\
(\mathrm{cm})\end{array}$ & 5.55 & \pm 0.72 & 5.55 & 5.46 & 5.64 \\
\hline API in boys & 0.52 & \pm 0.05 & 0.52 & 0.51 & 0.52 \\
\hline $\begin{array}{l}\text { Fourschette-Anus } \\
(\mathrm{cm})\end{array}$ & 1.44 & \pm 0.20 & 1.50 & 1.41 & 1.47 \\
\hline $\begin{array}{l}\text { Fourschette- } \\
\text { Coccyx (cm) }\end{array}$ & 3.73 & \pm 0.49 & 3.70 & 3.65 & 3.80 \\
\hline API in girls & 0.39 & \pm 0.04 & 0.38 & 0.38 & 0.39 \\
\hline *Cl: Confidence interval, API: Anal position index \\
\hline
\end{tabular}

girls and boys, respectively (Figure 2). The anus was found to be anteriorly located in nine (4\%) boys and seven (4\%) girls.

Table 3 presents the API measurement of the patients. The distance between the scrotal base to anus was $2.87 \pm 0.49 \mathrm{~cm}$ and the scrotal base to coccyx was $5.55 \pm 0.72 \mathrm{~cm}$ in boys. The posterior fourchette to anus was $1.44 \pm 0.20 \mathrm{~cm}$ and the posterior fourchette to coccyx was $3.73 \pm 0.49 \mathrm{~cm}$ in girls. The mean API was detected to be $0.52 \pm 0.05 \mathrm{~cm}$ in males and $0.39 \pm 0.04 \mathrm{~cm}$ in females. There was a direct correlation between the distance of scrotal base to the coccyx in boys and posterior fourchette to the anus in girls with increasing $\mathrm{BMI}$ and increasing gestational age (For gestational age boys $r=0.165$, $p=0.012$; girls $r=0.186, p=0.014$ ), (For BMI boys $r=0.241$, $p<0.01$; girls $r=0.343, p<0.01$ ).

The rate of the anterior location did not differ between genders. The API values were higher in males (median; 0.52$)$ than the girls (median; 0.38$)(p<0.01)$. No difference in API was detected when gestational age was considered. The API value in total had a direct correlation with the birth weight, height, and head circumference. There was no statistically significant relationship between the existence of anteriorly located anus and the time of first meconium passage in our study. The mean time for the first meconium passage was detected to be 12.4 hours and 10.8 hours in the anteriorly displaced anüs and normally located anus, respectively ( $p>0.05$ ).

The API did not have any statistically significant relation with gestational age-adjusted birth weight, type of delivery, presence of consanguinity ( $p>0.05$ in each variable).

\section{Discussion}

Hendren (13) and Leap (5) reported in 1978 that they detected a relation between idiopathic constipation and anteriorly located anus in some cases. But they did not mention the exact anal location. When making a comparison between the normal or anterior located anus, the API should be used as an objective parameter. For this reason, API has to be evaluated in neonates and infants, especially when the physical examination reveals lead to a spectrum location. Its anterior placement solely does not mean that the child has an ARM. The diagnosis of a lower type ARM should be made together with its relation to the sphincteric complex. This anterior displacement might create a tendency to constipation (14). Bornman et al. (7) defined that the anal position was affected in male neonates if there was an exposure to dichloro diphenyl dichloroethylene in earlier stages of pregnancy. This was also documented with experimental studies (7). Reisner et al. (8) defined the normal anal location and API with a simple measurement in 1984 . They reported that API for girls and boys should be $0.44 \pm 0.05$ and $0.58 \pm 0.06$, respectively in the neonatal period (8). While a study from Egypt mentioned an API value of 0.48 for boys and 0.34 for girls, they were defined to be 0.53 and 0.38 for Indian boys and girls, respectively $(14,15)$. In the literature, the mean API values range widely in different populations (0.43-0.58 in boys, $0.34-0.46$ in girls). The mean values in the presented series are suitable with these ranges 
previously reported (16-18). Besides measuring the API of the cases, we created a percentile scale different than the other studies.

The diagnosis of the anteriorly located anus was made when the API was $<0.34$ in girls and $<0.46$ in boys according to Reisner et al. (8). On the other hand, Davari and Hosseinpour (11) accepted the limit as $<0.44$ and $<0.53$ for girls and boys, respectively. In the presented study the fifth percentile is accepted as the base for defining anterior location. Although the mean values are appropriate with the literature data, the limits of the fifth percentile are a bit lower than the previous studies $(7,10,11,14)$. If the Reisner et al. (8) values were used in this series there would be 2.45 and 2.1 fold overdiagnoses in boys and girls, respectively as the lower limits of API in the Reisner et al. (8) study fall into the 5-25 percentile of ours and this was prevented by the modification presented.

The meconium passage was not affected in any patient presented in this study as all the neonates passed stool on the first day after birth regardless of their API. We detected that the API was higher in boys in all gestational age-adjusted weight groups and this finding is similar to the literature (11-12,17). Sharma et al. (19) also reported in their meta-analysis that API was higher in males.

The effect of the anteriorly located anus on constipation is evaluated in different studies $(18,20)$. Leape and Upadhyaya supported that it increased the incidence of constipation $(5,21)$. But Herek et al. (22) found that the incidence of constipation did not differ in two groups with the normal and anterior displaced anus. They included infants older than one month in their study and concluded that the anterior displacement, especially in girls, was a common variant (22).

We evaluated the anal position and created a percentile scale of API in a relatively high number of patients when compared with the published data. Using this scale diminished the number of cases that would be diagnosed to have an anteriorly displaced anus. This also aids in choosing the appropriate patients for referral to Pediatric Surgery to start the further examination. The API, by itself, does not reveal the existence of an ARM but will select the candidates for anal sphincter stimulation.

\section{Study Limitations}

The strength of the study is that it includes the highest number of patients in the literature. All the measurements in 405 cases were made by a single person and standardized. The limitation of this study is that it does not include long-term follow-up of the patients.

\section{Conclusion}

The measurement of API in neonates can be easily performed. This index is a noninvasive and useful modality to determine the abnormalities in the anal location. This study presents a percentile scale that more accurately differs the cases with an anomaly that should be further evaluated.

\section{Authorship Contributions}

Concept: S.T., E.Y., Design: S.T., E.Y., Data Collection or Processing: S.T., Analysis or Interpretation: S.T., E.Y., Literature Search: S.T., E.Y., Writing: S.T., E.Y.

Conflict of Interest: No conflict of interest was declared by the authors.

Financial Disclosure: The authors declared that this study received no financial support.

\section{References}

1. Gangopadhyay AN, Pandey V. Anorectal malformations. J Indian Assoc Pediatr Surg 2015;20:10-5.

2. Oh C, Youn JK, Han JW, Yang HB, Kim HY, Jung SE. Analysis of Associated Anomalies in Anorectal Malformation: Major and Minor Anomalies. J Korean Med Sci 2020;35:e98.

3. Rohrer L, Vial Y, Gengler C, Tenisch E, Alamo L. Prenatal imaging of anorectal malformations - 10-year experience at a tertiary center in Switzerland. Pediatr Radiol 2020;50:57-67.

4. Nakamura H, Puri P. Concurrent Hirschsprung's disease and anorectal malformation: a systematic review. Pediatr Surg Int 2020;36:21-4.

5. Leape LL, Ramenofsky ML. Anterior ectopic anus: a common cause of constipation in children. J Pediatr Surg 1978;13:627-30.

6. Weinberg G, Boley SJ. Anorectal continence and management of constipation. In: Ashcraft KW, Holder TM. Pediatric Surgery. Philadelphia: Saunders Company: 2000. p. 502-10.

7. Bornman MS, Chevrier J, Rauch S, et al. Dichlorodiphenyltrichloroethane exposure and anogenital distance in the Venda Health Examination of Mothers, Babies and their Environment (VHEMBE) birth cohort study, South Africa. Andrology 2016;4:608-15.

8. Reisner SH, Sivan Y, Nitzan M, Merlob P. Determination of anterior displacement of the anus in newborn infants and children. Pediatrics 1984;73:216-7.

9. Kauvar DR, Boley SJ. Anorektal continence and management of constipation. In: Ascgraft KW, Holder TM, editors. Pediatric Surgery. 2nd ed. Philadelphia: Saunders; 1993. p. 402-9.

10. Pena A, Hong AR. Anorektal malformations. In: Mattei $P$, editör. Surgical directives pediatric surgery. Philadelphia: Lippincott Williams\&Wilkins; 2003. p. 413-20.

11. Davari HA, Hosseinpour M. The anal position index: a simple method to define the normal position of the anus in neonate. Acta Paediatr 2006 Jul;95:877-80

12. Genç A, Taneli C, Tansuğ N, et al. Evaluation of the location of the anus by a modified technique in the neonate. J Pediatr Surg 2002;37:80-2. 
13. Hendren WH. Constipation caused by anterior location of the anus and its surgical correction. J Pediatr Surg 1978;13:50512.

14. Patel JN, Kumar A, Yadav PS, et al. The position of the anal dimple in newborns and infants with anorectal malformations and its correlation with the normal anal position. J Pediatr Surg 2018;53:1560-5.

15. Shahin $M$, Abdelsalam M. The anal position Index: a simple method to define the normal position of the anus in neonate its significance In diagnosis constipation. AAMJ 2011;9:37484.

16. Mohta A, Goel MR. Determination of anal position index. Indian Pediatr 2004;41:91-2.

17. Rerksuppaphol S, Rerksuppaphol L. Normal anal position index in Thai newborns. J Med Assoc Thai 2008;91:1839-44.
18. Bar-Maor JA, Eitan A. Determination of the normal position of the anus (with reference to idiopathic constipation). J Pediatr Gastroenterol Nutr 1987;6:559-61.

19. Sharma S, Perumal V, Sharma K, Gupta DK. Varied parameters and utility of the anal position index: a systematic review and meta-analysis. Pediatr Surg Int 2021;37:469-77.

20. Hendren WH. Constipation caused by anterior location of the anus and its surgical correction. J Pediatr Surg 1978;13:50512.

21. Upadhyaya P. Mid-anal sphincteric malformation, cause of constipation in anterior perineal anus. J Pediatr Surg 1984;19:183-6.

22. Herek O, Polat A. Incidence of anterior displacement of the anus and its relationship to constipation in children. Surg Today 2004;34:190-2. 